\title{
Transcriptome changes during fruit development and ripening of sweet orange (Citrus sinensis)
}

\author{
Keqin $\mathrm{Yu}^{1}$, Qiang $X \mathrm{u}^{1,2^{*}}$, Xinlei Da ${ }^{1}$, Fei Guo ${ }^{1}$, Yuduan Ding ${ }^{1}$ and Xiuxin Deng ${ }^{1,2^{*}}$
}

\begin{abstract}
Background: The transcriptome of the fruit pulp of the sweet orange variety Anliu (WT) and that of its red fleshed mutant Hong Anliu (MT) were compared to understand the dynamics and differential expression of genes expressed during fruit development and ripening.

Results: The transcriptomes of WT and MT were sampled at four developmental stages using an Illumina sequencing platform. A total of 19,440 and 18,829 genes were detected in MT and WT, respectively. Hierarchical clustering analysis revealed 24 expression patterns for the set of all genes detected, of which 20 were in common between MT and WT. Over 89\% of the genes showed differential expression during fruit development and ripening in the WT. Functional categorization of the differentially expressed genes revealed that cell wall biosynthesis, carbohydrate and citric acid metabolism, carotenoid metabolism, and the response to stress were the most differentially regulated processes occurring during fruit development and ripening.

Conclusion: A description of the transcriptomic changes occurring during fruit development and ripening was obtained in sweet orange, along with a dynamic view of the gene expression differences between the wild type and a red fleshed mutant.
\end{abstract}

\section{Background}

The typical course of fruit development involves expansion, sweetening and increasing pigmentation [1]. From the consumers' point of view, the appearance, texture and taste of the fruit are all of high importance. These properties involve attaining a suitable composition of sugars, organic acids, amino acids and carotenoids. The underlying mechanisms of fruit development and ripening have been extensively studied in tomato [2], but are not well explored in non-climacteric fruits. Citrus is a widely grown fruit crops, which exhibits non-climacteric ripening behaviour. Its fruit contains a juicy pulp made of vesicles within segments [3]. The growth and development of the citrus fruit can be divided into three stages: cell division, an expansion phase involving cell enlargement and water accumulation, and the ripening stage [4]. In the latter stage, carotenoids and other soluble solids are accumulated, chlorophyll is lost, the cell wall is

\footnotetext{
* Correspondence: xuqiang@mail.hzau.edu.cn; xxdeng@mail.hzau.edu.cn 'Key Laboratory of Horticultural Plant Biology of Ministry of Education, Huazhong Agricultural University, Wuhan 430070, China Full list of author information is available at the end of the article
}

extensively modified, the organic acid content is reduced, and the concentration of a number of volatiles increases.

Citrus fruit provides a convenient vehicle to study gene regulation during non-climacteric fruit development and ripening. In grape (Vitis vinifera), another non-climacteric fruit, several comprehensive mRNA expression profiling studies have been presented to describe fruit development and ripening [5-8], while in citrus, an EST sequencing project showed that $20 \%$ of the sequences were metallothionein [9]. Application of a citrus cDNA microarray has suggested that unique genetic regulatory networks arise during fruit development [10], while a more global transcriptome analysis was able to identify ethylene-responsive genes in the mandarin fruit [11]. More recently, a comprehensive study of the clementine fruit transcriptome has proposed a mechanism for citrate utilization [12]. However, these transcriptomic studies of fruit development in citrus have mainly been based on microarray analysis, the next generation sequencing technology provides new opportunities for more accurate and powerful deep transcriptome analysis of fruit development.

The ripening of citrus fruit is accompanied by carbohydrate build-up, acid reduction, and carotenoid 
accumulation. Citrus fruits accumulate most of their sucrose in the juice cells [13]. Glucose is decomposed via glycolysis and the pentose phosphate pathway (OPP). As the major acid present in citrus fruit, citric acid contributes $>90 \%$ of the total organic acid content. Citric acid synthesis is thought to take place in the mitochondria via the tricarboxylic acid (TCA) cycle. Although the genes encoding some of the key enzymes (specially, citrate synthase (CS), aconitase [14], and NADP-isocitrate dehydrogenase (NADP-IDH) [15]) have been isolated, their activity cannot completely account for variation in the level of citric acid in citrus fruit [16]. Carotenoids are also important components of the citrus fruit, and their composition and content in sweet orange fruits have been extensively studied $[17,18]$. Cross-talk between carotenoid, sugar and organic acid metabolism has been documented $[19,20]$. The presence of sucrose may promote colour break [21], while its deficiency delays lycopene accumulation in tomato [22]. The down-regulation of CS and NAD-dependent IDH results in a decrease in the levels of both organic acids and carotenoids [23].

The fruit of the bud mutant Hong Anliu is characterized by a high sucrose and low citric acid level and its tendency to accumulate lycopene is responsible for the red pigmentation of its pulp [20]. The mutant appears to be highly isogenic with its progenitor wild type variety Anliu, as revealed by a genotypic analysis based on microsatellites and AFLPs. The mutant has therefore provided a platform to study cross-talk between primary (sugar and organic acid synthesis) and secondary (carotenoid synthesis) metabolism enzymes, which are fundamental in the determination of citrus fruit quality. Suppressive subtraction hybridization combined with cDNA microarray analysis has been applied to determine that the differentially expressed genes were mainly enriched in the stage of 170 DAF (days after flowering) in the mutant fruit [24]. At this stage, a total of 582 genes were found to be differentially expressed between the wild type Anliu (hereafter WT) and Hong Anliu (hereafter MT) as revealed by RNA-seq analysis [25]. However, how genes are dynamically and differentially expressed during fruit development and ripening has not yet been determined. Here, the developmental changes of fruit transcriptome of sweet orange were investigated.

\section{Methods}

\section{Plant material and RNA preparation}

WT and MT plants were both cultivated in the same orchard at the Institute of Citrus Research (Guilin, Guangxi Province, China), with the same climatic conditions. Fruit samples were harvested at 120,150, 190, and 220 DAF (days after flowering) from three different trees in 2009. At each developmental stage, ten representative fruits were sampled from each tree. The pulp was separated from the peel, and the pulp was sliced. The sliced WT pulps samples were combined with one another (similarly for the MT samples), snap-frozen in liquid nitrogen and kept at $-80^{\circ} \mathrm{C}$ until required $[24,25]$. One aliquot was used to extract RNA isolation, as described previously [26]. The remainder of the powder was used for the determination of sugar and organic acid composition and concentration, and the content of $\mathrm{H}_{2} \mathrm{O}_{2}$.

\section{RNA-seq and functional assignment}

The WT and MT fruit pulp harvested at 120, 150, 190, and 220 DAF was subjected to RNA-seq using an Illumina Genome Analyzer at Beijing Genomics Institute (Shenzhen) in 2009. The abundance of each tag was normalized to one transcript per million (TPM) for between sample comparison purposes. The raw data was filtered to remove low quality sequences including ambiguous nucleotides, adaptor sequences, and below 3 TPM, as described previously [25]. The sequencing data can be accessed at the website: http://www.ncbi.nlm.nih.gov/geo/query/acc.cgi? token=dxqjxoygumyauzm\&acc $=$ GSE22505. To link the expressed signatures to known genes from orange, the TIGR unigene dataset (http://compbio.dfci.harvard.edu/ tgi/cgi-bin/tgi/gimain.pl?gudb=orange) was used as a reference database. The $\mathrm{Z}$-score method using the p-value as a statistical significance index [27] was applied to identify differentially expressed genes. A cluster analysis was performed according to Eisen et al. [28]; the $\log _{2}$ of TPM for each gene was used for the hierarchical clustering analysis. Gene Ontology (GO) categorization was carried out as described previously [25]. The ultra-geometric test was applied to perform GO enrichment analysis. In the significance analysis of the enrichment of a GO item, the pvalue represents the probability of satisfying the hypothesis that the designated genes involved in the GO item has not been enriched (statistical significance at $\mathrm{P}=0.05$ ).

\section{Real-time quantitative RT-PCR}

The differential expression of a selection of the genes identified as being differentially expressed was validated by applying real-time quantitative RT-PCR (qRT-PCR). The sequences of the primer pairs (designed using Primer Express 3.0 (Applied Biosystems, Foster City, CA, USA)) are listed in additional file 1. All qRT-PCRs were performed using an ABI 7500 Real Time System (Applied Biosystems) using the actin gene as the reference [20]. Primers for both the target gene and the reference were diluted in SYBR GREEN PCR Master Mix (Applied Biosystems) and $20 \mu \mathrm{L}$ of the reaction mix were added to each well. Reactions were performed via an initial incubation at $50^{\circ} \mathrm{C}$ for $2 \mathrm{~min}$ and at $95^{\circ} \mathrm{C}$ for $10 \mathrm{~min}$, and then cycled at $95^{\circ} \mathrm{C}$ for $15 \mathrm{~s}$, and $60^{\circ} \mathrm{C}$ for $60 \mathrm{~s}$ for 40 cycles. The resulting data were handled by the instrument on- 
board software Sequence Detector Version 1.3.1 (Applied Biosystems).

\section{Analysis of sugar, organic acid and $\mathrm{H}_{2} \mathrm{O}_{2}$}

Soluble sugar and organic acid composition and concentrations were determined by gas chromatography (GC) using $3 \mathrm{~g}$ of the powdered pulp as described previously [29] with minor modifications. The powder was suspended in chilled $80 \%$ methanol and then held in a $75^{\circ} \mathrm{C}$ water bath for $30 \mathrm{~min}$. After a $2 \mathrm{~h}$ ultrasonic extraction and centrifugation at $4000 \mathrm{~g}$ for $10 \mathrm{~min}$, the supernatant was collected and $1 \mathrm{~mL}$ internal standard $(2.5 \% \mathrm{w} / \mathrm{v}$ phenyl- $\beta$ $\mathrm{D}$-glucopyranoside, $2.5 \% \mathrm{w} / \mathrm{v}$ methyl- $\alpha-\mathrm{D}$-glucopyranoside) was added. The solution was made up to $50 \mathrm{~mL}$ with $80 \%$ methanol, and a $2 \mathrm{~mL}$ aliquot was centrifuged at $12000 \mathrm{~g}$ for $15 \mathrm{~min}$. A $0.5 \mathrm{~mL}$ aliquot of this final supernatant was vacuum-dried and then re-dissolved in $800 \mu \mathrm{L}$ $2 \% \mathrm{w} / \mathrm{v}$ hydroxylamine hydrochloride in pyridine at $75^{\circ} \mathrm{C}$ for $1 \mathrm{~h}$. Then $400 \mu \mathrm{L}$ hexamethyldisilazane and $200 \mu \mathrm{L}$ trimethylchlorosilane were added and the sample was held at $75^{\circ} \mathrm{C}$ for $2 \mathrm{~h}$. A $0.5 \mu \mathrm{L}$ aliquot was used for GC analysis in an Agilent $6890 \mathrm{~N}$ device (Santa Clara, CA, USA) equipped with a flame ionization detector. A capillary column (HP$5,5 \%$ phenyl-methylpolysiloxane, $30 \mathrm{~m} \times 25 \mu \mathrm{m}$ i.d. $\times$ $0.1 \mu \mathrm{m}$ ) was employed, with nitrogen as the carrier gas at a flow rate of $45 \mathrm{~mL} / \mathrm{min}$, and flow-rates of hydrogen and air set to $40 \mathrm{~mL} / \mathrm{min}$ and $450 \mathrm{~mL} / \mathrm{min}$, respectively. Sugars and organic acids were identified through a comparison of retention times using standard compounds from Sigma (St. Louis, MO, USA). The concentration of $\mathrm{H}_{2} \mathrm{O}_{2}$ was measured using a hydrogen peroxide detection kit supplied by Nanjing Jiancheng Institute of Biological Technology (Nanjing, China). A 0.8 g sample of powdered pulp was suspended in $7.2 \mathrm{ml}$ saline $(0.90 \% \mathrm{w} / \mathrm{v}$ of $\mathrm{NaCl})$ and centrifuged for $10 \mathrm{~min}$ at $10,000 \mathrm{~g}$. The intensity of yellow complex formed by the reaction of molybdate and $\mathrm{H}_{2} \mathrm{O}_{2}$, as measured spectrophotometrically at $405 \mathrm{~nm}$, was used to assess the concentration of $\mathrm{H}_{2} \mathrm{O}_{2}$. Three replicates were conducted for each sample.

\section{Results}

The fruit transcriptome sampled at four developmental stages

In total, eight cDNA preparations were sequenced from fruit pulp sampled at 120, 150, 190, and 220 DAF from WT and MT. The average number of tags produced for each library was 4.01 million (Table 1). The raw data were submitted and available from the NCBI/GEO repository (accession number GEO: GSE22505; website: http://www. ncbi.nlm.nih.gov/geo/query/acc.cgi?token=dxqjxoygumyauzm\&acc $=$ GSE22505). After filtering, the number of robust tags per library ranged from 2.5 to 4.3 million, and the number of distinct tags from 61,000 to 113,000 . A saturation analysis (additional file 2) demonstrated that as sequencing depth was increased, the number of new distinct tags decreased, but only until the number of sequences had reached 2.5 million. We concluded therefore that the libraries were all fully saturated and hence large enough for gene expression analysis. The distribution of distinct tag abundance and total tag number exhibited very similar tendencies for all eight libraries (additional file $3)$. Transcripts which accounted for nearly $60 \%$ of the total number were in less than $7 \%$ of the categories, and transcripts that accounted for $40 \%$ of the categories were less than $5 \%$ of the total number, indicating that only a few genes were expressed at a high level.

\section{Transcriptome changes during fruit development and ripening}

To map tags to known genes, a reference citrus unigene dataset containing 26,826 contigs and 73,607 singletons was used. The procedure identified between $68.1 \%$ and $76.2 \%$ of the tags (additional file 4), of which 20,155 to 36,173 (31.8\% to $33.1 \%$ ) produced unambiguous identifications (one tag mapping to one gene). The libraries were relatively uniform with respect to mapping efficiency. A total of 18,829 genes were detected in at least one of the four stages in the wild type sweet orange, of which 8,825 genes were expressed in all the four stages. In this study, we solely used the wild type sweet orange as a model to demonstrate the transcriptome changes during fruit development and ripening. Three genes were most highly expressed in wild type, two of which were encoded a stress-response protein (one $22 \mathrm{kDa}$ polypeptide response to low temperature stress) and a heat shock protein, while the function of the third one (F28C11.8) is unknown. Changes in the transcriptome during fruit development and ripening were examined by cluster analysis of gene expression patterns, which arranged the 18,829 genes into 22 groups (Figure 1); the 10,005 (53.1\%) genes expressed in three or less of the three stages fell into groups 1 to 11 . The largest group (20) comprised the 3,075 (16.3\%) genes whose expression increased continuously during fruit development and ripening; this group included the genes encoding sucrose phosphate synthase, cysteine proteinase and a sucrose transporter. The second largest group (10) contained the 2,970 (15.8\%) genes which were not expressed at 120 DAF but maintained a stable expression level at other three developmental stages. The 2,618 (13.9\%) genes in group 2 were not expressed at 120 and 190 DAF. The cluster analysis also revealed that the abundance of $89.7 \%$ of the transcripts detected in the WT pulp varied over the course of fruit development and ripening (Figure 1). Many of the transcripts were single stage-specific (additional file 5). A comparison of expression patterns between WT (Figure 1) and MT (additional file 6) revealed that 20 of the groups were common to both, while $97.5 \%$ of the genes expressed in MT showed a similar expression 
Table 1 Summary of the RNA-seq data collected from MT and WT at each of four selected fruit developmental stages

\begin{tabular}{|c|c|c|c|c|c|c|c|c|c|}
\hline Category & & 120DAF & & 150DAF & & 190DAF & & 220DAF & \\
\hline \multirow[t]{2}{*}{ Total Sequence Collected } & WT & 2718771 & & 4184144 & & 4417154 & & 4564850 & \\
\hline & MT & 3998867 & & 3254246 & & 4275571 & & 4745537 & \\
\hline \multirow[t]{2}{*}{ Low Quality Tags } & WT & 187214 & $6.89 \%$ & 393141 & $9.40 \%$ & 356403 & $8.07 \%$ & 397623 & $8.71 \%$ \\
\hline & MT & 359939 & $8.99 \%$ & 263844 & $8.11 \%$ & 401180 & $9.38 \%$ & 451906 & $9.52 \%$ \\
\hline \multirow[t]{2}{*}{ Reliable Tags } & WT & 2531557 & $93.11 \%$ & 3791003 & $90.60 \%$ & 4060751 & $91.93 \%$ & 4167227 & $91.29 \%$ \\
\hline & MT & 3638928 & $91.00 \%$ & 2990402 & $91.89 \%$ & 3874391 & $90.62 \%$ & 4293631 & $90.48 \%$ \\
\hline \multirow[t]{2}{*}{ Distinct tags } & WT & 60841 & $2.24 \%$ & 111341 & $2.66 \%$ & 95693 & $2.17 \%$ & 101845 & $2.23 \%$ \\
\hline & MT & 101301 & $2.53 \%$ & 92270 & $2.84 \%$ & 104280 & $2.44 \%$ & 113006 & $2.38 \%$ \\
\hline
\end{tabular}

DAF, days after flowering.

pattern to that in WT (the exceptions belonged to groups 13 and 19).

\section{Differentially expressed genes during fruit development and ripening}

Of the 18,829 genes detected in the WT, 9,377, 7,886, and 7,757 were differentially expressed between $120 \mathrm{DAF}$ and 150 DAF, 150 DAF and 190 DAF, and 190 DAF and 220 DAF, respectively. Of these, $36.7 \%$ were assigned to one of 18 GO categories (Figure 2). The categories "metabolic process", "cellular process", "establishment of localization", "localization", "biological regulation", "pigmentation", and "response to stimulus" based on biological process captured most of these genes. Several of the differentially expressed genes were associated with cell wall metabolism and softening (Table 2). A gene encoding pectinesterase (TC14614) showed a decrease in expression during fruit development and ripening, consistent with the modification of pectin which occurs during ripening. A xyloglucan endotransglycosylase gene (TC9277) was up-regulated during fruit development and ripening, while another (TC25537) was only detectable at the early stage of fruit development. The abundance of three expansin (EY741042, TC20787, and EY738078) and three alphaexpansin (EY727139, EY743186, and EY699153) transcripts increased during fruit development and ripening. Some genes involved in sucrose metabolism, the TCA cycle and carotenoid biosynthesis were found to be differentially expressed (Table 2). The expression of a sucrose phosphate synthase gene family member (EY677217) increased during ripening, and its expression profile correlated well with the rise in total soluble solids. Related genes encoded CS (EY703799), aconitase-iron regulated protein 1 (CB293814), phytoene synthase (PSY) (EY722043) and phytoene desaturase (PDS) (TC3). Some of the differentially expressed genes were associated with stress response (Table 2): these included genes encoding a heat shock protein and various metallothioneins. Most of the metallothionein genes were up-regulated in the later stages of ripening. Three cysteine protease genes (EY718215, $T C 22740$, and $E Y 707198$ ), were also highly expressed at the late stage of fruit development and ripening. Also, the expression of a valencene synthase gene (TC363) increased during fruit development and ripening.

\section{Developmental difference between fruit transcriptome of MT and WT}

The comparison between the transcriptomes of WT and MT identified 6,540 genes showing a two-fold or greater difference in expression level at 120 DAF, 3,529 at 150 DAF, 4,601 at 190 DAF, and 3,289 at 220 DAF. Application of the Z-score method [27] suggested that the expression of $634,568,540$, and 616 of these was significantly different at $\mathrm{p}<0.05$ and $\mid \log _{2}$ Ratio $\mid \geq 1$ in the four developmental stages, respectively (additional file 7). The top ten differentially expressed genes in each of the four developmental stages have been listed in additional file 8. Many encode stress-related products, such as cysteine protease $\mathrm{Cp} 5$ and metallothionein-like protein. At all the four developmental stages the number of up-regulated genes was less than that of down-regulated genes (Figure 3).

When the expression profiles of the genes differentially expressed between MT and WT were subjected to a cluster analysis (additional file 9), over one half (492/ 883) turned out to be up-regulated in MT at all the developmental stages except 150 DAF. Some examples of this large cluster included genes encoding $\mathrm{Cu} / \mathrm{Zn}$ superoxide dismutase (TC12069), ascorbate peroxidase (EY685405, TC22775 and TC14669), MYB1 (EY649968) and plastidic glucose 6-phosphate/phosphate translocator (EY722703). Only five genes were detected as differentially expressed at all four stages; one encoded a cysteine protease (Cp5) (TC5370), which had been reported exhibiting the acid-activatable cysteine protease forms [30], three had no assigned functions, and one shared no homology with any entry in. The five genes could be classified into two groups (two genes in one group, three genes in the other), with their expression patterns of being opposite to each other but with both groups having a turning point at 150 DAF (additional file 10). 


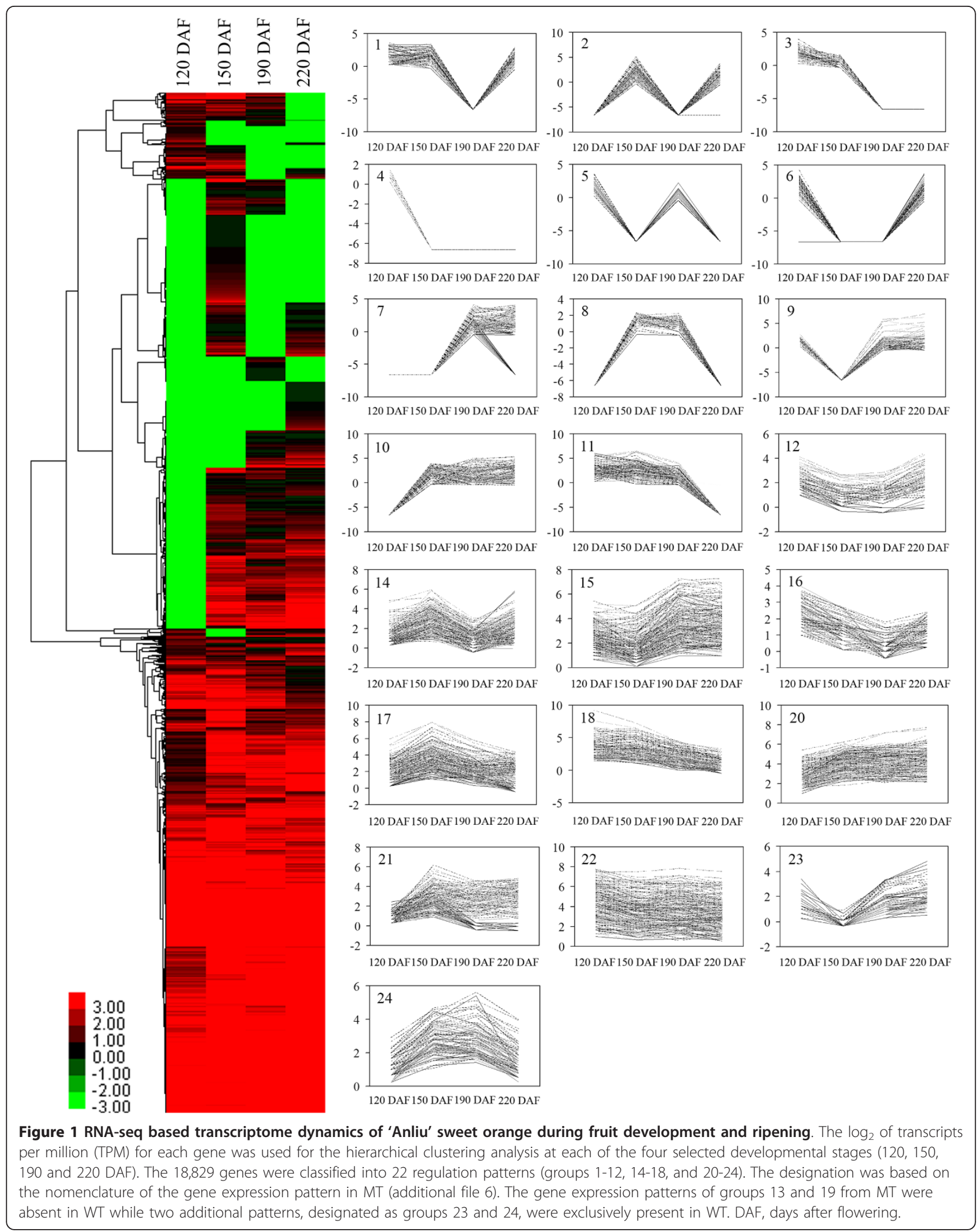




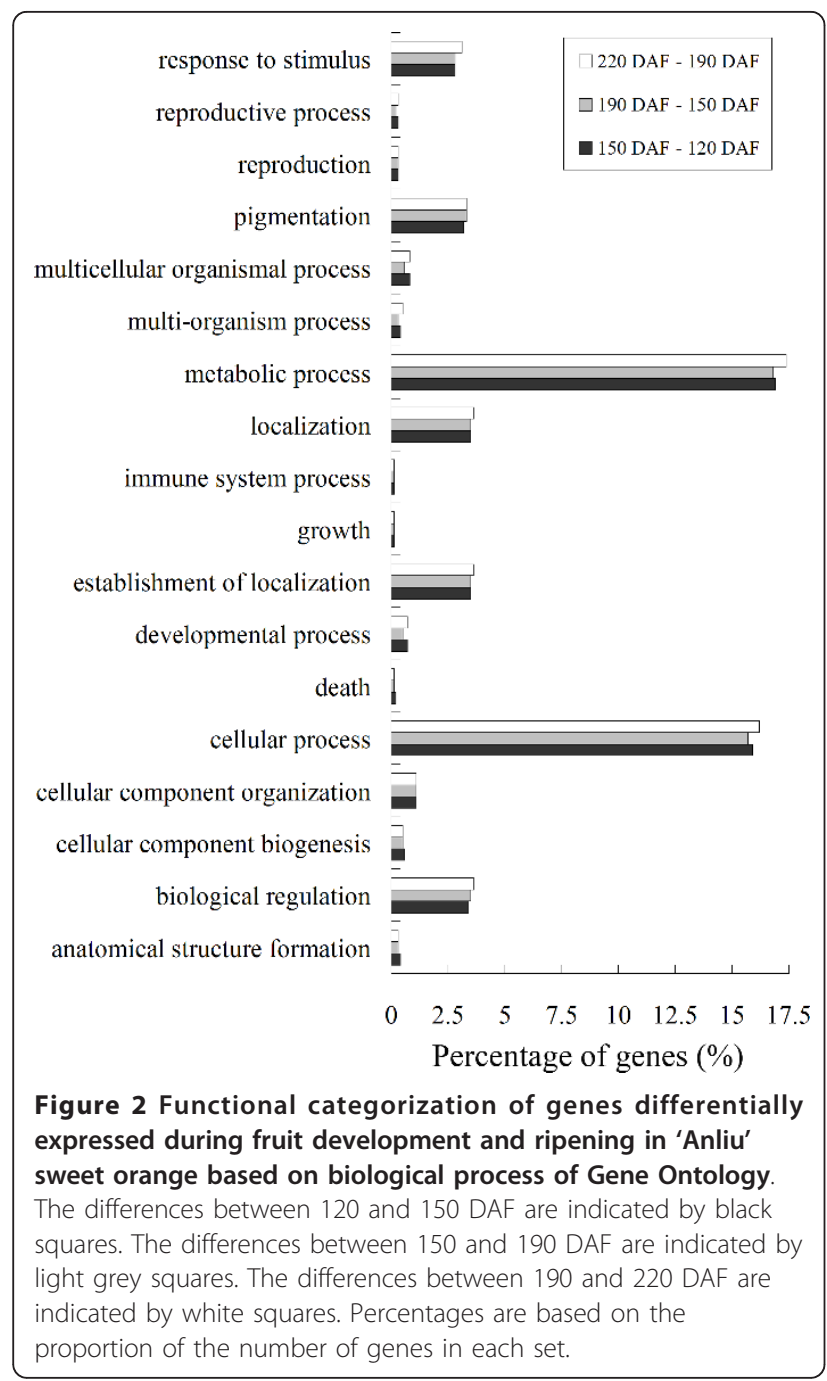

The GO categories of the set of differentially expressed genes (additional file 11) revealed that most encoded products associated with "protein binding", "hydrolase activity", "transferase activity" and "transporter activity". At the 150 DAF stage, the most common categories were "signal transducer activity" and "electron carrier activity". GO enrichment analysis was also carried out to identify which key processes were altered in MT (Table 3). The genes encoding phytoene synthase (EY722043) and $\zeta$-carotene desaturase (ZDS) (TC15628) involved in carotenoid metabolic process were enriched at 150 DAF in MT compared to WT, and those encoding capsanthin/capsorubin synthase (CCS) (TC5834 and TC9367) were also enriched at $150 \mathrm{DAF}$ in MT.

Verification of differentially expressed genes during fruit development and ripening

RNA sampled from fruit of MT and WT at the four selected stages of fruit development and ripening provided the template for qRT-PCR validation of the sequencebased transcription profiles for 22 of the differentially expressed genes (Figure 4). Linear regression [(RNA-seq value $)=a($ RT $-\mathrm{PCR}$ value $)+b]$ analysis showed an overall correlation coefficient of 0.8379 , indicating a good correlation between transcript abundance assayed by real-time PCR and the transcription profile revealed by RNA-seq data (Figure 4E).

\section{Changes in fruit soluble sugars, organic acids, carotenoids and $\mathrm{H}_{2} \mathrm{O}_{2}$ content}

Since the expression of a number of genes implicated in carbohydrate metabolism and mitochondria-related citric acid metabolism varied greatly during fruit development and ripening, an attempt was made to monitor the dynamics of pulp soluble sugar and organic acid content. The content of soluble sugars increased markedly during the late stages of fruit development and ripening in both WT and MT (Figure 5A). The concentrations of glucose and fructose remained rather constant up to $150 \mathrm{DAF}$, and thereafter tended to be higher in MT than in WT. The concentration of sucrose was higher in MT than in WT throughout fruit development and ripening. The citric acid content fluctuated, but was lower in MT than in WT at all developmental stages (Figure 5B). The concentration of quinic acid decreased substantially over the course of fruit development and ripening, but did not differ between WT and MT. Carotenoids and lycopene both accumulated over time in MT, but remained at a low level in WT (Figure 5C). Finally, $\mathrm{H}_{2} \mathrm{O}_{2}$ content fell as the fruit developed and ripened, but was higher in MT than in WT at 120 DAF (Figure 5D).

\section{Discussion}

Transcriptome dynamics during fruit development and ripening

Fruit ripening is a highly coordinated, genetically programmed and irreversible process which involves a series of physiological, biochemical, and organoleptic changes allowing for the development of an edible ripe fruit [31]. Fruit ripening in citrus is accompanied by carbohydrate build-up, acid reduction, carotenoid accumulation and chlorophyll degradation [32]. The bud mutant MT produces fruit with high sucrose and lycopene, but low citric acid content [20]. Here, transcriptome changes over the course of fruit development and ripening in MT and WT were monitored and annotated. We must point out that we collected samples from three different trees and pooled for RNA-seq analysis for each developmental stage. We did not include biological replicates considering that we used a pair of genotypes (WT and MT) and the data from WT and MT could corroborate to each other to some extent. We sequenced each pool once technically since the next generation sequencing data are highly replicable with 
Table 2 List of 10 genes involved in major processes associated with fruit development and ripening based on Gene Ontology categorization

\begin{tabular}{|c|c|c|c|c|c|}
\hline Go term & $\begin{array}{l}\text { Gene } \\
\text { identifier }\end{array}$ & Gene discription & $\begin{array}{l}\text { 150vs120 Fold } \\
\text { change }\end{array}$ & $\begin{array}{l}\text { 190vs150 Fold } \\
\text { change }\end{array}$ & $\begin{array}{l}\text { 220vs190 Fold } \\
\text { change }\end{array}$ \\
\hline carotenoid & TC14030 & Zeta-carotene desaturase & 4.94 & - & 2.19 \\
\hline metabolic & TC15628 & Zeta-carotene desaturase & $6.59 / 0$ & - & 2.93 \\
\hline \multirow[t]{8}{*}{ process } & TC19375 & carotenoid isomerase & 3.33 & 0.19 & - \\
\hline & TC3 & Phytoene desaturase & 6.18 & - & 2.19 \\
\hline & TC4815 & Epsilon lycopene cyclase & 3.1 & - & - \\
\hline & TC5834 & Capsanthin/capsorubin synthase & 0.35 & 8.39 & 0.55 \\
\hline & CN187831 & Zeta-carotene desaturase & - & - & $1.2 / 0$ \\
\hline & EY722043 & Phytoene synthase & - & 1.36 & - \\
\hline & TC26011 & Zeta-carotene desaturase & - & $0 / 3.43$ & $1.2 / 0$ \\
\hline & TC5 & Lycopene beta-cyclase & - & 2.88 & - \\
\hline cell wall & EY676350 & Reversibly glycosylated protein & 0.13 & 9.53 & 1.81 \\
\hline \multirow[t]{9}{*}{ organization } & EY727139 & Alpha-expansin 3 & $0 / 1.19$ & - & - \\
\hline & TC4398 & Pectinesterase-3 precursor & 0.57 & 1.43 & 0.31 \\
\hline & EY700757 & Pectinesterase-1 precursor & - & - & 0.26 \\
\hline & EY743186 & Alpha-expansin precursor & - & $1.48 / 0$ & - \\
\hline & TC14614 & Pectinesterase PPE8B precursor & - & 0.09 & 0/0.99 \\
\hline & TC25537 & Xyloglucan endotransglucosylase & - & $0 / 1.58$ & - \\
\hline & EY738078 & Expansin & - & $5.17 / 0$ & - \\
\hline & EY679620 & Cellulose synthase & 0.3 & 0.33 & 0.2 \\
\hline & EY679934 & Cellulose synthase & 0.51 & 0.23 & - \\
\hline sucrose & TC11046 & Sucrose synthase & 0.32 & 0.39 & 0.41 \\
\hline metabolic & EY743126 & Sucrose-phosphate synthase 1 & $7.65 / 0$ & - & 1.77 \\
\hline \multirow[t]{6}{*}{ process } & TC14378 & Sucrose-phosphate synthase 1 & 3.28 & - & 2.53 \\
\hline & TC20096 & Sucrose synthase & $1.85 / 0$ & $0 / 1.85$ & $1.44 / 0$ \\
\hline & EY719381 & Sucrose-phosphate synthase 1 & - & - & 0.37 \\
\hline & CX044648 & Sucrose synthase & - & 0.1875 & - \\
\hline & EY667747 & Sucrose-phosphate synthase & - & - & - \\
\hline & EY677217 & Sucrose-phosphate synthase & - & - & 8.43 \\
\hline oxygen and & EY680864 & Superoxide dismutase & $5.28 / 0$ & - & 0.25 \\
\hline reactive & EY741543 & Superoxide dismutase [Cu-Zn] & 1.78 & & 1.69 \\
\hline oxygen & TC12069 & $\mathrm{Cu} / \mathrm{Zn}$ superoxide dismutase & $32.18 / 0$ & 0.62 & - \\
\hline \multirow[t]{7}{*}{ species } & TC14743 & $\begin{array}{l}\text { Cu/Zn-superoxide dismutase copper chaperone } \\
\text { precursor }\end{array}$ & 2.71 & - & - \\
\hline & TC2154 & Superoxide dismutase [Cu-Zn] & 2.67 & 0.36 & 3.72 \\
\hline & TC22348 & Superoxide dismutase & 4.22 & - & - \\
\hline & TC23992 & Superoxide dismutase & $11.34 / 0$ & 0.61 & 2.47 \\
\hline & CN189455 & $\begin{array}{l}\text { Superoxide dismutase }[\mathrm{Mn}] \text {, mitochondrial } \\
\text { precursor }\end{array}$ & $3.69 / 0$ & 2.07 & - \\
\hline & TC4680 & Superoxide dismutase & 3.55 & 2.87 & 1.48 \\
\hline & TC19068 & $\begin{array}{l}\text { Cu/Zn-superoxide dismutase copper chaperone } \\
\text { precursor }\end{array}$ & - & - & - \\
\hline Response & CF836240 & Peroxidase precursor & 0.31 & - & $0 / 3.69$ \\
\hline \multirow[t]{9}{*}{ to stress } & CK701553 & Heat shock protein 70 & 0.19 & - & 0.26 \\
\hline & EY676086 & Serine/threonine-protein phosphatase PP1 & $2.37 / 0$ & - & - \\
\hline & EY735114 & Plastid enolase & 4.68 & - & 2 \\
\hline & TC18825 & 2-oxoacid dehydrogenase family protein & 3.97 & 0.54 & 2.81 \\
\hline & TC21917 & Methionine synthase & $2.11 / 0$ & - & - \\
\hline & TC3575 & 22 kDa polypeptide & 1.12 & - & 0.92 \\
\hline & EY730377 & Group 5 late embryogenesis abundant protein & - & - & 2.03 \\
\hline & TC20176 & Osmotin-like & - & - & 0/0.99 \\
\hline & TC8117 & Thaumatin-like protein & - & 20.91 & 3.63 \\
\hline
\end{tabular}

For each gene, the number given at each stage indicates that the level of expression differed significantly compared with the level at the former stage; -, no significant difference; 0 , zero detectable expression, for example, $6.59 / 0$ indicates that the expression was not detected at the earlier sampling stage, but showed a transcript level of 6.59 at the current one. 


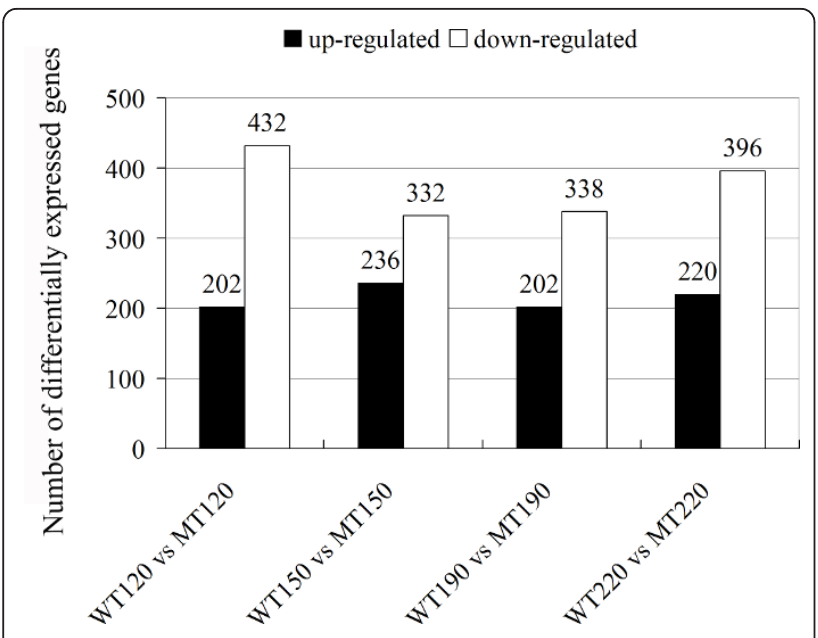

Figure 3 Distribution of genes differentially expressed between 'Anliu' sweet orange and its red flesh mutant at each of four selected stages of fruit development and ripening. The number of up-regulated genes was less than that of down-regulated ones at all the four stages. WT120 vs MT120 indicates a comparison between WT and MT at 120 DAF.

relatively little technical variation [33]. We also used realtime qRT-PCR to verify the transcription profile revealed by RNA-seq data (Figure 4), with an overall correlation coefficient of 0.8379 which indicated the RNA-seq data was reliable. The RNA-seq approach detected a similar number of genes $(18,829$ genes in WT and 19,440 genes in MT) in both genotypes, with no apparent difference between the global number of genes expressed in the two genotypes at any of the four stages of fruit development and ripening sampled (additional file 4). The WT and MT patterns of gene expression were also largely alike (20 of the 24 expression patterns were similar). Thus, we believed that overall picture of the transcriptome captured by RNA-seq is robust.

An overwhelming proportion of the genes identified (84.8\% in MT and $89.7 \%$ in WT) varied in their level of expression over the course of fruit development and ripening, reflecting the occurrence of a massive genetic re-programming. A large number of these genes were expressed in a stage-specific manner, which implicates their involvement in physiological processes which take place only at a specific developmental stage(s). A major group of the differentially expressed genes was involved in cell wall modification, which is not surprising since the major textural changes associated with the softening of fruit are due to enzyme-mediated alterations in the structure and composition of the cell wall [34], especially the cell walls of juice sacs in citrus. Changes in the activity of several cell wall-related genes were known to result in the abnormal development of juice sac granulation [35,36], while modifications in cell wall structure or in the components of the membranes of the segments and juice sacs during fruit development and ripening clearly influenced the formation of the fruit pulp melting characteristic [37]. One of the cell wall-related genes revealed here encoded a pectinesterase, an enzyme which modifies the assembly and disassembly of pectin, a common component of the primary cell wall. In tomato, the gene for pectinesterase was highly expressed prior to ripening, and was down-regulated by ethylene as ripening begins [38]. Here, the expression of the gene encoding the pectinesterase PPE8B precursor decreased as the WT fruit matured (Figure 4A), while in the blood orange, the expression of a pectinesterase gene has been shown to increase during fruit development and ripening [39]. It might be due to the different members identified in the

Table 3 Gene ontology enrichment analysis for the genes differentially expressed between WT and MT during fruit development and ripening

\begin{tabular}{|c|c|c|c|c|c|}
\hline Category & Library pair & Enriched GO terms & $\begin{array}{l}\text { Cluster } \\
\text { frequency }\end{array}$ & $\begin{array}{l}\mathrm{P}- \\
\text { value }\end{array}$ & Genes in group \\
\hline \multirow[t]{6}{*}{$\begin{array}{l}\text { Molecular } \\
\text { function }\end{array}$} & WT150vsMT150 & $\begin{array}{l}\text { capsanthin/capsorubin } \\
\text { synthase activity }\end{array}$ & $1.2 \%$ & 0.003 & TC5834, TC9367 \\
\hline & & sulfotransferase activity & $1.5 \%$ & 0.010 & TC5490, DN620599 \\
\hline & WT190vsMT190 & $\begin{array}{l}\text { transferase activity, } \\
\text { transferring glycosyl } \\
\text { groups }\end{array}$ & $9.3 \%$ & 0.006 & $\begin{array}{l}\text { EY691346, TC18663, TC10188, TC8764, TC320, TC9277, TC11658, EY679857, } \\
\text { TC24546, TC11943, TC8402, CK939135, TC15309, TC22218, EY661193 }\end{array}$ \\
\hline & & $\begin{array}{l}\text { protein } \mathrm{N} \text {-terminus } \\
\text { binding }\end{array}$ & $1.2 \%$ & 0.031 & TC2476, TC10188 \\
\hline & WT220vsMT220 & fructokinase activity & $1.5 \%$ & 0.019 & TC9238, EY702245, TC17456 \\
\hline & & sulfotransferase activity & $1.0 \%$ & 0.030 & TC5490, DN620599 \\
\hline \multirow[t]{3}{*}{$\begin{array}{l}\text { Biological } \\
\text { process }\end{array}$} & WT120vsMT120 & cell wall organization & $5.1 \%$ & 0.021 & $\begin{array}{l}\text { TC4981, CK933828, DN618740, EY725863, TC18738, TC3660, TC12562, } \\
\text { EY746957, TC14614 }\end{array}$ \\
\hline & & $\begin{array}{l}\text { protein import into } \\
\text { nucleus, docking }\end{array}$ & $1.7 \%$ & 0.034 & EY701416, EY733548, DY305879 \\
\hline & WT150vsMT150 & $\begin{array}{l}\text { carotenoid metabolic } \\
\text { process }\end{array}$ & $3.3 \%$ & 0.043 & EY722043, TC15628, TC5834, TC9367 \\
\hline
\end{tabular}



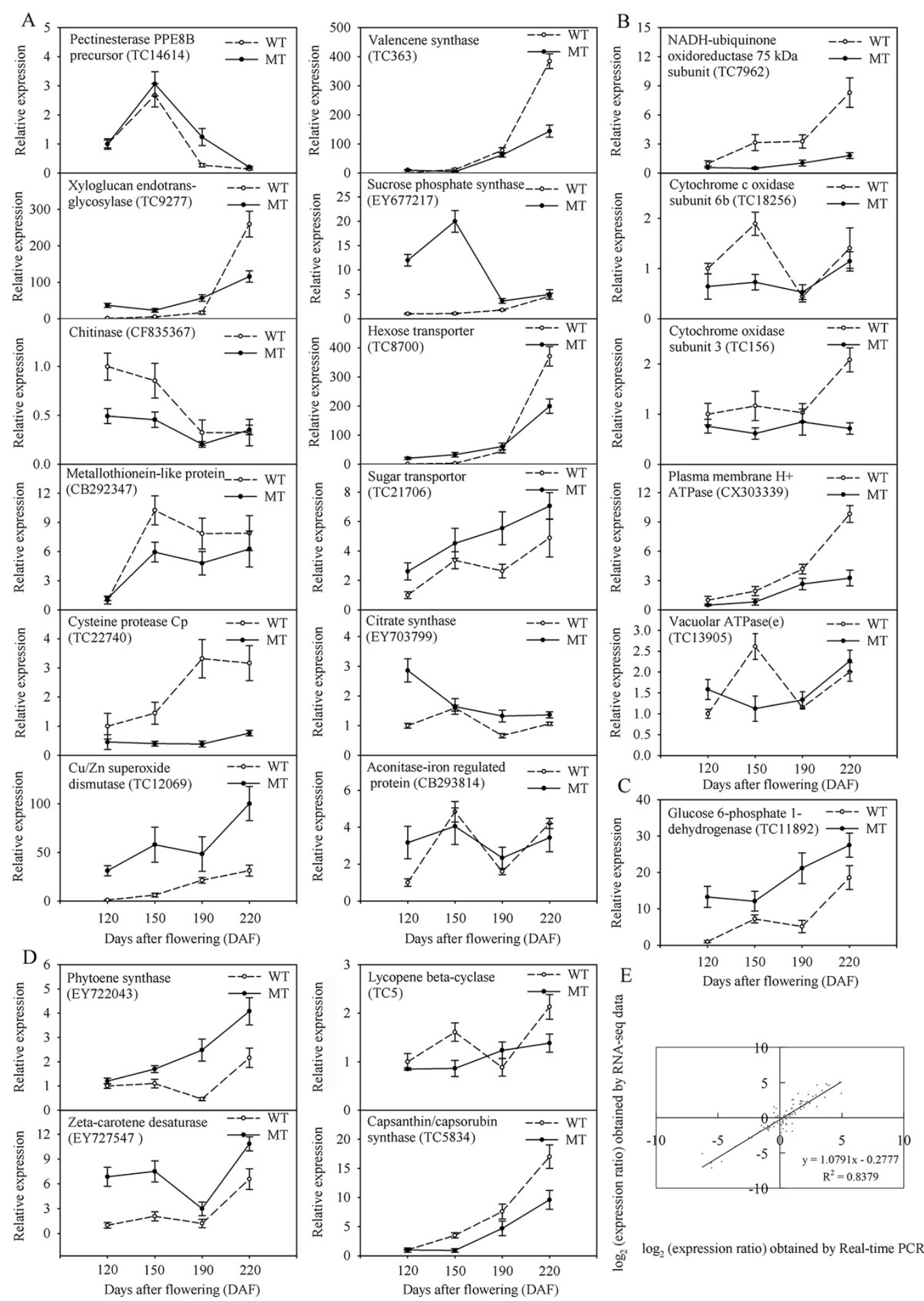

$\log _{2}$ (expression ratio) obtained by Real-time PCR

Figure 4 qRT-PCR validation of differential expression. The figure shows transcript levels of 22 genes, of which 12 probably associated with fruit development and ripening (A) and 10 with oxidative phosphorylation (B), the OPP pathway (C) or carotenoid biosynthesis (D) in MT (solid line) and WT (broken line). The $y$-axis records the relative gene expression levels analyzed by qRT-PCR. Bars represent the standard error $(n=3)$. (E) A comparison between the gene expression ratios obtained from RNA-seq data and qRT-PCR. The RNA-seq $\log _{2}$ of expression ratio ( $y$-axis) have been plotted against developmental stages ( $x$-axis). 


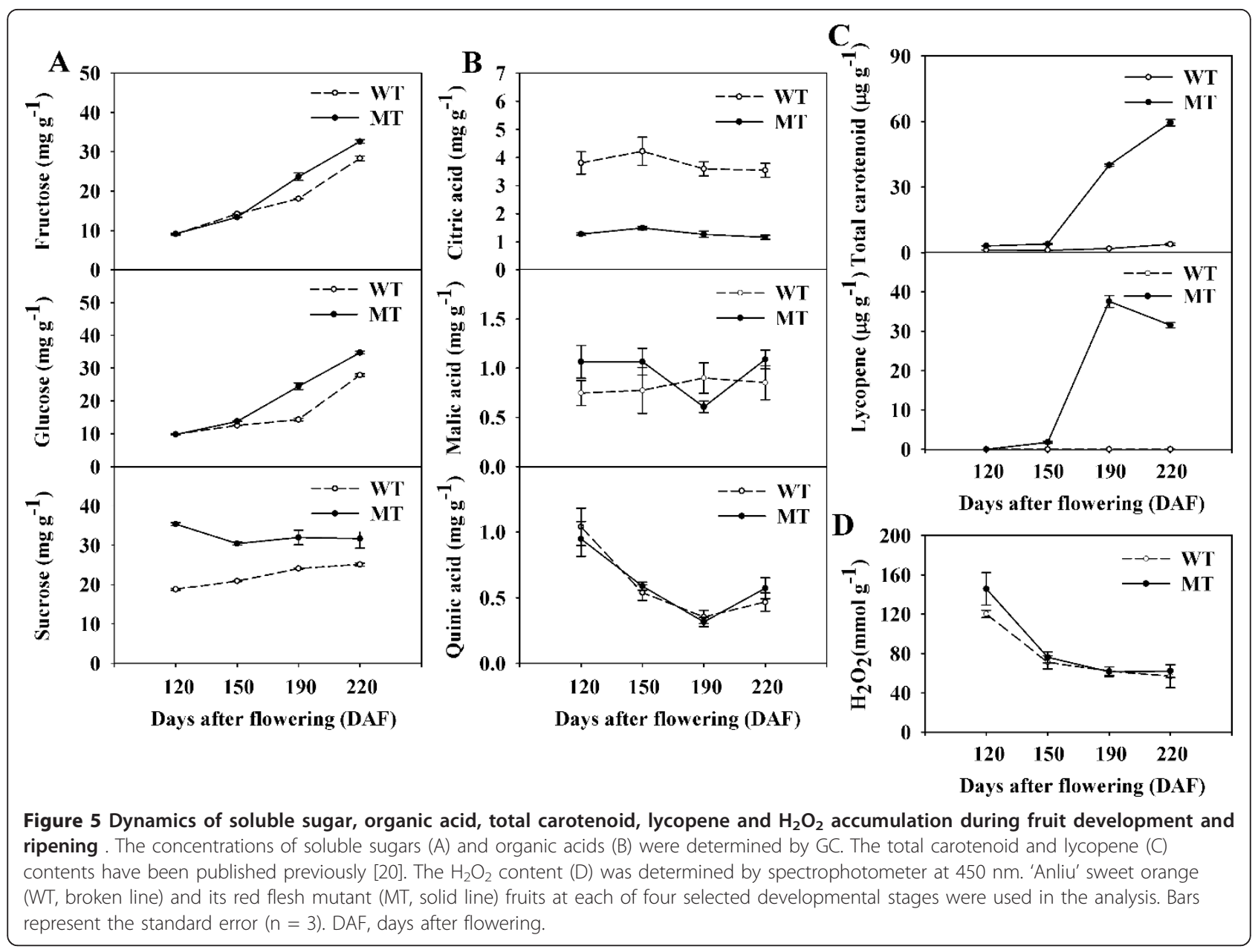

two studies. The hemicellulose xyloglucan is a common component of the cell wall, and is hydrolysed and transglycosylated by xyloglucan endotransglycosylase in growing tissues and ripening fruits [40]. Here, a gene encoding this enzyme was up-regulated during fruit development and ripening (Figure 4A), indicating its probable role in cell wall degradation during ripening. Both the early enlargement of the citrus fruit driven by cell expansion and the later ripening process require the presence of expansins to loosen the cell walls [41], and several genes encoding expansins were detected in the present study and their expression was higher at the later stages of fruit development and ripening.

The accumulation of carbohydrates represents one of the most obvious changes which occur during citrus fruit development and ripening. The perceived changes in expression of genes involved in carbohydrate metabolism here were consistent with the findings of other transcriptomic analyses in citrus [12]. The type of sugar deposited to a high level in the cell vacuole in citrus is predominantly sucrose, unlike in grape, where it is glucose and fructose [6]. Reflecting this difference, the expression profile of the gene encoding sucrose synthase in citrus [12] was rather different from that in the grape [6]. Nevertheless, in both species, sugar is important for the regulation of colour development, and perhaps also for other ripening processes [42]. It was notable that the gene encoding a sucrose phosphate synthase was induced during fruit development and ripening, perhaps because the activity of this enzyme may be required for the resynthesis of sucrose to allow its further transport to the vacuole [43]. Of some interest also was the behaviour of a gene encoding valencene synthase, an enzyme the activity of which was known to be induced by ethylene, and which was part of the natural ripening process in citrus [11]. Valencene is an important component of the aroma of the ripe sweet orange fruit. Both in the present experiments (Figure 4A) and elsewhere [44], valencene synthase transcript accumulated in the ripening fruit.

Molecular processes involved in the formation of the fruit traits of red flesh sweet orange

Suppressive subtraction hybridization, in combination with cDNA microarray analysis, has identified a set of 
267 genes which were differentially expressed between MT and WT [24]. RNA-seq technology is more capable of identifying a nearly complete inventory of transcripts and by this method a total of 582 genes were found to be differentially expressed between WT and MT at the stage of 170 DAF [25]. In the current study, we tested on four developmental stages of WT and MT and extended our understanding of the global and dynamic changes during fruit development and ripening in MT and WT. Almost all of the members of the 267 gene set revealed by SSH strategy were also identified in the present study, although some discrepant expression patterns were apparent between this new data set and previously assembled microarray-based set. For example, the abundance of the transcript encoding cysteine protease, which appeared to differ between MT and WT in both studies, was documented by the microarray analysis as being lower at all developmental stages, whereas it appeared to be higher at 150 DAF in MT in the present study (additional file 10).

The major biological processes occurring in the mitochondria (TCA cycle, coupling electron transfer, and oxidative phosphorylation) were remarkably altered in MT. The intermediates of the TCA cycle can be channelled into the syntheses of fats, terpenoids, porphyrins, nucleotides, and amino acids. In MT, the level of citric acid, the major organic acid present in citrus fruit, was consistently around 25\% that present in WT fruit (Figure 5). However, no major difference was detected in the expression of the genes encoding CS and aconitase-iron regulated protein (Figure 4A), two predominant enzymes involved in the TCA cycle. Five differentially expressed genes, all associated with mitochondria-related processes (coupling electron transfer and oxidative phosphorylation) were downregulated in MT compared with WT (Figure 4B). These included the genes encoding a NADH-ubiquinone oxidoreductase $75 \mathrm{kDa}$ subunit (TC7962), cytochrome $C$ oxidase (TC18256), and cytochrome oxidase subunit 3 (TC156), suggesting that MT mitochrondria were capable of less efficient electron transport than that WT ones. If, as a result, flux through the TCA cycle is decreased, the accumulation of citric acid is likely to be compromised. In addition, PDS and ZDS catalyzing desaturation of phytoene to lycopene involve net electron transfer [45]. In tomato, a $\mathrm{NAD}(\mathrm{P}) \mathrm{H}$ dehydrogenase complex which participating in electron transfer was involved in carotenoid biosynthetic pathway [46], suggesting the possible exist of cross-talk between electron transfer and carotenoid accumulation in sweet orange.

In the plant cell, the mitochondrial electron transport chain is a major site of reactive oxygen species (ROS) production [47]. Here, the concentration of one of the primary ROS molecules $\left(\mathrm{H}_{2} \mathrm{O}_{2}\right)$ was higher in MT than that in WT at 120 DAF (Figure 5D). The delicate balance between antioxidant defence and ROS production can be disrupted by either compromised antioxidant defence or the inhibition of electron flow [48]. Here, the primary anti-oxidant enzymes (SOD, APX and GR) were more active in MT than in WT pulp, suggesting that the level of oxidative stress may be greater in MT than in WT [49]. The expression of a large number of stress-related genes was also substantially different in MT and WT (additional file 8). Functioning as an important ROS scavenging pathway, the ascorbate-glutathione cycle requires the cofactor $\mathrm{NADPH}$, which is provided by the OPP pathway [50]. This pathway is also a major source of NADPH for many biosynthetic processes, including carotenoid biosynthesis [51], in non-photosynthetic organs such as the fruit. The gene encoding glucose 6phosphate dehydrogenase, which is considered as the first and rate-limiting enzyme of the OPP pathway in all cells [52], was up-regulated in MT. A statistical analysis of the qRT-PCR result confirmed that the level of transcription of this gene was significantly higher in MT than in WT, especially at 120 DAF (Figure 4C). Carotenoid biosynthesis, another effective anti-oxidative process [53], was also higher in MT than in WT. Lycopene is the most potent antioxidant among the carotenoids [54]. The expression level of several carotenoid biosynthesis genes, encoding namely PSY, ZDS, lycopene $\beta$-cyclase (LCYb) and CCS, was greatly changed in MT. PSY is generally accepted to be a rate-limiting enzyme in carotenoid biosynthesis pathway. The CCS product is an enzyme which is mechanistically similar to LCYb, and the low transcript level of CCS may well be responsible for the accumulation of lycopene in red grapefruits (Citrus paradisi) [19]. The qRT-PCR analysis confirmed that both upstream genes (PSY and ZDS) were up-regulated and both downstream ones ( $L C Y b$ and $C C S$ ) down-regulated in MT (Figure 4D), consistent with the mechanism regulating lycopene accumulation in tomato [55].

\section{Conclusion}

The present study has provided a dynamic view of the transcriptome during fruit development and ripening of a sweet orange red-fleshed mutant and its progenitor wild type. Cell wall biosynthesis, carbohydrate metabolism, the TCA cycle, and carotenoid biosynthesis were all differentially regulated during fruit development and ripening. These differentially regulated processes may well be important for the formation of the pleiotropic fruit trait of Hong Anliu sweet orange.

\section{Additional material}

Additional file 1: The primer sequence information. This file listed the primers sequences used for real-time quantitative RT-PCR validation of RNA-seq data. 
Additional file 2: The saturation evaluations of the eight libraries in this study. This file contained the information of the saturation evaluations of the RNA-seq tags in the eight libraries (MT and WT at four selected fruit developmental stages) against sequencing depth. The results revealed that with the increase of total sequence number (sequencing depth), the number of genes identified increased, but the number stabilized once the number of sequences reached 2.5 million, indicating enough information has been included in the RNA-seq data.

Additional file 3: Distribution of total tags number (A) and distinct tags number (B) in MT and WT at 120, 150, 190, and 220 DAF. This file showed the distribution of the number of total tags and distinct tags obtained in MT and WT at different developmental stages.

Additional file 4: Summary of tags mapped against a reference set of sweet orange unigenes. This file contained the summary result of tags mapping against a reference set of sweet orange unigenes.

Additional file 5: Number of stage-specific genes expressed in MT and WT. This file contained the summary result of stage-specific genes number in MT and WT.

Additional file 6: Transcriptome dynamics in MT during fruit development and ripening. This file contained the result of the hierarchical cluster analysis of genes expression profiles in MT. The $\log _{2}$ of transcripts per million (TPM) for each gene was used for the hierarchical clustering analysis at four developmental stages $(120,150$, 190 and 220 DAF). In all, 19,440 genes were classified into 22 regulatory patterns, designated groups 1-22.

Additional file 7: List of differentially expressed genes between MT and WT. The table contained information of the differentially expressed genes with expression difference $>2$, and genes differentially expressed at 0.05 significance level at each of the four fruit developmental stages.

\section{Additional file 8: The ten most differentially expressed genes} between MT and WT at each of the four selected fruit developmental stages. This file listed the ten most differentially expressed genes between MT and WT at different developmental stages, with their expression ratios between MT and WT, also containing simple annotation information.

Additional file 9: Dynamics patterns of gene expression of a set of genes differentially expressed between MT and WT at each of the four selected fruit developmental stages. This file contained the result of the hierarchical cluster analysis of expression profiles of differentially expressed genes between MT and WT at different developmental stages. The $\log _{2}$ of the ratio between the MT and the WT TPM for each gene was used to perform the cluster analysis.

Additional file 10: The five genes differentially expressed at all four selected developmental stages. This file contained the pattern of genes which were differentially expressed at all selected stages. At each stage $(120,150,190$ and $220 \mathrm{DAF})$, the $\log _{2}$ of the ratio between the MT and the WT TPM for each gene is represented.

Additional file 11: Functional categorization of genes differentially expressed between WT and MT. This file showed the distribution of GO categories of differentially expressed genes between WT and MT at the four selected stages of fruit development and ripening. The categorization was based on molecular activity of Gene Ontology items. Percentages are based on the proportion of the number of genes in each set.

\section{Acknowledgements}

This work was supported by the National Basic research program of China (973 program; No. 2011CB100601), and the National Natural Science Foundation of China (No. 30830078 and 31071779).

\section{Author details}

'Key Laboratory of Horticultural Plant Biology of Ministry of Education, Huazhong Agricultural University, Wuhan 430070, China. ${ }^{2}$ National Key Laboratory of Crop Genetic Improvement, Huazhong Agricultural University, Wuhan 430070, China.

\section{Authors' contributions}

KQY, QX and XLD were responsible for generating the RNA-seq data and for the interpretation of the data. KQY carried out qRT-PCR experiments and measured sugar, organic acid and $\mathrm{H}_{2} \mathrm{O}_{2}$ content, and drafted the manuscript. QX conceived the study, participated in its design and helped to draft the manuscript. FG and YDD participated in the statistical analyses. XXD proposed and supervised the research. All authors read and approved the final manuscript.

Received: 24 September 2011 Accepted: 10 January 2012

Published: 10 January 2012

\section{References}

1. Coombe BG: The Development of Fleshy Fruits. Annu Rev Plant Physiol 1976, 27:207-228.

2. Fei ZJ, Tang XM, Alba RM, White JA, Ronning CM, Martin GB, Tanksley SD, Giovannoni JJ: Comprehensive EST analysis of tomato and comparative genomics of fruit ripening. Plant I 2004, 40(1):47-59.

3. Iglesias DJ, Cercós M, Colmenero-Flores JM, Naranjo MA, Ríos G, Carrera E, Ruiz-Rivero O, Lliso I, Morillon R, Tadeo FR, Talon M: Physiology of citrus fruiting. Braz J Plant Physiol 2007, 19:333-362.

4. Bain JM: Morphological, anatomical, and physiological changes in the developing fruit of the Valencia orange, Citrus sinensis (L) Osbeck. Aust J Bot 1958, 6(1):1-23.

5. Mohammad A, Shangwu C, Yechun W, Oliver Y, Laszlo K, Wenping Q: Berry skin development in Norton grape: Distinct patterns of transcriptional regulation and flavonoid biosynthesis. BMC Plant Biol 2011, 11:7.

6. Deluc LG, Grimplet J, Wheatley MD, Tillett RL, Quilici DR, Osborne C, Schooley DA, Schlauch KA, Cushman JC, Cramer GR: Transcriptomic and metabolite analyses of Cabernet Sauvignon grape berry development. BMC genomics 2007, 8(1):429.

7. Pilati S, Perazzolli M, Malossini A, Cestaro A, Demattè L, Fontana P, Dal Ri A, Viola R, Velasco R, Moser C: Genome-wide transcriptional analysis of grapevine berry ripening reveals a set of genes similarly modulated during three seasons and the occurrence of an oxidative burst at veraison. BMC genomics 2007, 8(1):428.

8. Zenoni S, Ferrarini A, Giacomelli E, Xumerle L, Fasoli M, Malerba G, Bellin D, Pezzotti M, Delledonne M: Characterization of transcriptional complexity during berry development in Vitis vinifera using RNA-Seq. Plant Physiol 2010, 152(4):1787.

9. Moriguchi T, Kita M, Hisada S, Endo-Inagaki T, Omura M: Characterization of gene repertoires at mature stage of citrus fruits through random sequencing and analysis of redundant metallothionein-like genes expressed during fruit development1. Gene 1998, 211(2):221-227.

10. Shimada T, Fuiii H, Endo T, Yazaki J, Kishimoto N, Shimbo K, Kikuchi S, Omura M: Toward comprehensive expression profiling by microarray analysis in citrus: monitoring the expression profiles of 2213 genes during fruit development. Plant Sci 2005, 168(5):1383-1385.

11. Fujii H, Shimada T, Sugiyama A, Nishikawa F, Endo T, Nakano M, Ikoma Y, Shimizu T, Omura M: Profiling ethylene-responsive genes in mature mandarin fruit using a citrus 22K oligoarray. Plant Sci 2007, 173(3):340-348.

12. Cercós M, Soler G, Iglesias DJ, Gadea J, Forment J, Talón M: Global analysis of gene expression during development and ripening of citrus fruit flesh. A proposed mechanism for citric acid utilization. Plant Mol Biol 2006, 62(4):513-527.

13. Soule J, Grierson W: Anatomy and physiology. In Fresh citrus fruits. Edited by: W. Wardowski, S. Nagy, and W. Grierson. AVI, Westport, Conn; 1986:1-22.

14. Sadka A, Dahan E, Cohen L, Marsh KB: Aconitase activity and expression during the development of lemon fruit. Physiol Plantarum 2000, 108(3):255-262.

15. Sadka A, Dahan E, Or E, Cohen L: NADP(+)-isocitrate dehydrogenase gene expression and isozyme activity during citrus fruit development. Plant Sci 2000, 158(1-2):173-181.

16. Katz E, Fon M, Lee YJ, Phinney BS, Sadka A, Blumwald E: The citrus fruit proteome: insights into citrus fruit metabolism. Planta 2007, 226(4):989-1005

17. Wang YC, Chuang YC, Hsu HW: The flavonoid, carotenoid and pectin content in peels of citrus cultivated in Taiwan. Food Chem 2008, 106(1):277-284. 
18. Fanciullino AL, Dhuique-Mayer $C$, Froelicher $Y$, Talón $M$, Ollitrault $P$, Morillon R: Changes in carotenoid content and biosynthetic gene expression in juice sacs of four orange varieties (Citrus sinensis) differing in flesh fruit color. J Agr Food Chem 2008, 56(10):3628-3638.

19. Alquézar $B$, Zacarías $L$, Rodrigo MJ: Molecular and functional characterization of a novel chromoplast-specific lycopene $\beta$-cyclase from Citrus and its relation to lycopene accumulation. J Exp Bot 2009, 60(6):1783-1797.

20. Liu Q, Xu J, Liu YZ, Zhao XL, Deng XX, Guo LL, Gu JQ: A novel bud mutation that confers abnormal patterns of lycopene accumulation in sweet orange fruit (Citrus sinensis L. Osbeck). J Exp Bot 2007, 58(1516):4161-4171.

21. Huff A: Sugar Regulation of Plastid Interconversions in Epicarp of Citrus Fruit. Plant Physiol 1984, 76:307-312.

22. Télef N, Stammitti-Bert L, Mortain-Bertrand A, Maucourt M, Carde JP, Rolin D, Gallusci P: Sucrose deficiency delays lycopene accumulation in tomato fruit pericarp discs. Plant Mol Biol 2006, 62:453-469.

23. Sienkiewicz-Porzucek A, Nunes-Nesi A, Sulpice R, Lisec J, Centeno DC, Carillo P, Leisse A, Urbanczyk-Wochniak E, Fernie AR: Mild reductions in mitochondrial citrate synthase activity result in a compromised nitrate assimilation and reduced leaf pigmentation but have no effect on photosynthetic performance or growth. Plant Physiol 2008, 147(1):115-127.

24. Liu Q, Zhu AD, Chai LJ, Zhou WJ, Yu KQ, Ding J, Xu J, Deng X: Transcriptome analysis of a spontaneous mutant in sweet orange [Citrus sinensis (L.) Osbeck] during fruit development. J Exp Bot 2009, 60(3):801-813.

25. Xu Q, Yu KQ, Zhu AD, Ye JL, Liu Q, Zhang JC, Deng XX: Comparative transcripts profiling reveals new insight into molecular processes regulating lycopene accumulation in a sweet orange (Citrus sinensis) red-flesh mutant. BMC Genomics 2009, 10:540.

26. Liu YZ, Liu Q, Tao NG, Deng XX: Efficient isolation of RNA from fruit pee and pulp of ripening navel orange (Citrus sinensis Osbeck). J HAU 2006, 25:300-304.

27. Kal AJ, van Zonneveld AJ, Benes V, van den Berg M, Koerkamp MG, Albermann K, Strack N, Ruijter JM, Richter A, Dujon B, et al: Dynamics of gene expression revealed by comparison of serial analysis of gene expression transcript profiles from yeast grown on two different carbon sources. Mol Biol Cell 1999, 10(6):1859-1872.

28. Eisen MB, Spellman PT, Brown PO, Botstein D: Cluster analysis and display of genome-wide expression patterns. Proc Natl Acad Sci USA 1998, 95(25):14863-14868.

29. Bartolozzi F, Bertazza G, Bassi D, Cristoferi G: Simultaneous determination of soluble sugars and organic acids as their trimethylsilyl derivatives in apricot fruits by gas-liquid chromatography. J Chromatogr A 1997, 758(1):99-107.

30. North MJ, Nicol K, Sands TW, Cotter DA: Acid-activatable cysteine proteinases in the cellular slime mold Dictyostelium discoideum. J Biol Chem 1996, 271(24):14462.

31. Prasanna V, Prabha TN, Tharanathan RN: Fruit Ripening Phenomena-An Overview. Crit Rev Food Sci Nutr 2007, 47(1):1-19.

32. Talon M, Gmitter FG: Citrus genomics. Int J Plant Genomics 2008, 2008:528361.

33. Marioni JC, Mason CE, Mane SM, Stephens M, Gilad Y: RNA-seq: an assessment of technical reproducibility and comparison with gene expression arrays. Genome research 2008, 18(9):1509-1517.

34. Goulao LF, Oliveira CM: Cell wall modifications during fruit ripening: when a fruit is not the fruit. Trends Food Sci Tech 2008, 19(1):4-25.

35. Singh R: 65-year research on citrus granulation. Ind J Hort 2001, 58(12):112-144.

36. Sharma RR, Saxena SK: Rootstocks influence granulation in Kinnow mandarin (Citrus nobilis C. deliciosa). Sci Hort 2004, 101(3):235-242.

37. Waldron KW, Parker ML, Smith AC: Plant cell walls and food quality. Compr Rev Food Sci Food saf 2003, 2(4):128-146.

38. Giovannoni JJ: Genetic regulation of fruit development and ripening. Plant Cell 2004, 16:S170.

39. Licciardello C, Russo MP, Vale' G, Recupero RG: Identification of differentially expressed genes in the flesh of blood and common oranges. Tree Genet Genomes 2008, 4(2):315-331.

40. Catala C, Rose JKC, York WS, Albersheim P, Darvill AG, Bennett AB: Characterization of a tomato xyloglucan endotransglycosylase gene that is down-regulated by auxin in etiolated hypocotyls. Plant Physiol 2001, 127(3):1180.

41. Brummell DA, Harpster MH, Dunsmuir P: Differential expression of expansin gene family members during growth and ripening of tomato fruit. Plant Mol Biol 1999, 39(1):161-169.

42. Castellarin SD, Gambetta GA, Wada H, Shackel KA, Matthews MA: Fruit ripening in Vitis vinifera: spatiotemporal relationships among turgor, sugar accumulation, and anthocyanin biosynthesis. J Exp Bot 2011.

43. Komatsu A, Moriguchi T, Koyama K, Omura M, Akihama T: Analysis of sucrose synthase genes in citrus suggests different roles and phylogenetic relationships. J Exp Bot 2002, 53(366):61.

44. Sharon-Asa L, Shalit M, Frydman A, Bar E, Holland D, Or E, Lavi U, Lewinsohn E, Eyal $Y$ : Citrus fruit flavor and aroma biosynthesis: isolation, functional characterization, and developmental regulation of Cstps1, a key gene in the production of the sesquiterpene aroma compound valencene. Plant J 2003, 36(5):664-674.

45. Mayer MP, Beyer P, Kleinig H: Quinone compounds are able to replace molecular oxygen as terminal electron acceptor in phytoene desaturation in chromoplasts of Narcissus pseudonarcissus L. Eur J Biochem 1990, 191(2):359-363.

46. Nashilevitz S, Melamed-Bessudo C, Izkovich Y, Rogachev I, Osorio S, Itkin M, Adato A, Pankratov I, Hirschberg J, Fernie AR: An Orange Ripening Mutant Links Plastid NAD (P) H Dehydrogenase Complex Activity to Central and Specialized Metabolism during Tomato Fruit Maturation. Plant Cell 2010, 22(6):1977-1997

47. Moller IM: Plant mitochondria and oxidative stress: Electron transport, NADPH turnover, and metabolism of reactive oxygen species. Annu Rev Plant Physiol Plant Mol Biol 2001, 52:561-591.

48. Turrens JF: Mitochondrial formation of reactive oxygen species. J Physiol London 2003, 552(2):335-344.

49. Pan ZY, Liu Q, Yun Z, Guan R, Zeng WF, Xu Q, Deng XX: Comparative proteomics of a lycopene-accumulating mutant reveals the important role of oxidative stress on carotenogenesis in sweet orange (Citrus sinensis [L.] osbeck). Proteomics 2009, 9(24):5455-5470.

50. May MJ, Vernous T, Leaver C, Van Montagu M, Inzé D: Glutathione homeostasis in plants: implications for environmental sensing and plant development. J Exp Bot 1998, 49:649-667.

51. Neuhaus HE, Emes MJ: Nonphotosynthetic metabolism in plastids. Annu Rev Plant Physiol Plant Mol Biol 2000, 51:111-140.

52. Stryer L: Biochemistry. W.H.Freeman and Co., San Francisco, CA; 31989.

53. Couee I, Sulmon C, Gouesbet G, El Amrani A: Involvement of soluble sugars in reactive oxygen species balance and responses to oxidative stress in plants. J Exp Bot 2006, 57(3):449-459.

54. Clinton SK: Lycopene: Chemistry, Biology, and Implications for Human Health and Disease. Nutr Rev 1998, 56(2):35-51.

55. Giuliano G, Bartley GE, Scolnik PA: Regulation of carotenoid biosynthesis during tomato development. Plant Cell 1993, 5(4):379.

doi:10.1186/1471-2164-13-10

Cite this article as: Yu et al.: Transcriptome changes during fruit development and ripening of sweet orange (Citrus sinensis). BMC Genomics 2012 13:10.

\section{Submit your next manuscript to BioMed Central and take full advantage of:}

- Convenient online submission

- Thorough peer review

- No space constraints or color figure charges

- Immediate publication on acceptance

- Inclusion in PubMed, CAS, Scopus and Google Scholar

- Research which is freely available for redistribution

Submit your manuscript at www.biomedcentral.com/submit
C Biomed Central 